University of Wollongong

Research Online

Australian Institute for Innovative Materials -

Papers

Australian Institute for Innovative Materials

$1-1-2016$

\title{
Silicon monoxide-a convenient precursor for large scale synthesis of near infrared emitting monodisperse silicon nanocrystals
}

\author{
Wei Sun \\ University of Toronto \\ Chenxi Qian \\ University of Toronto \\ Xiao Sherri Cui \\ University of Toronto \\ Liwei Wang \\ Guangxi University, University of Toronto \\ Muan Wei \\ University of Toronto
}

See next page for additional authors

Follow this and additional works at: https://ro.uow.edu.au/aiimpapers

Part of the Engineering Commons, and the Physical Sciences and Mathematics Commons

\footnotetext{
Research Online is the open access institutional repository for the University of Wollongong. For further information
} contact the UOW Library: research-pubs@uow.edu.au 


\title{
Silicon monoxide-a convenient precursor for large scale synthesis of near infrared emitting monodisperse silicon nanocrystals
}

\begin{abstract}
While silicon nanocrystals ( $\mathrm{ncSi}$ ) embedded in silicon dioxide thin films have been intensively studied in physics, the potential of batch synthesis of silicon nanocrystals from the solid-state disproportionation of $\mathrm{SiO}$ powder has not drawn much attention in chemistry. Herein we describe some remarkable effects observed in the diffraction, microscopy and spectroscopy of SiO powder upon thermal processing in the temperature range $850-1100{ }^{\circ} \mathrm{C}$. Quantum confinement effects and structural changes of the material related to the size of the silicon nanocrystals nucleated and grown in this way were established by Photoluminescence (PL), Raman, FTIR and UV-Visible spectroscopy, PXRD and STEM, pinpointing that the most significant disproportionation transformations happened in the temperature range between 900 and $950^{\circ} \mathrm{C}$. With this know-how a high yield synthesis was developed that produced polydispersions of decylcapped, hexane-soluble silicon nanocrystals predominantly with near infrared (NIR) PL. Using sizeselective precipitation, these polydispersions were separated into monodisperse fractions, which allowed their PL absolute quantum yield (AQY) to be studied as a function of silicon nanocrystal size. This investigation yielded volcano-shaped plots for the AQY confirming the most efficient PL wavelength for $\mathrm{ncSi}$ to be located at around $820-830 \mathrm{~nm}$, which corresponded to a size of 3.5-4.0 nm. This work provides opportunities for applications of size-selected near infrared emitting silicon nanocrystals in biomedical imaging and photothermal therapy.
\end{abstract}

\section{Keywords}

monoxide, nanocrystals, convenient, precursor, large, scale, synthesis, near, infrared, emitting, silicon, monodisperse

Disciplines

Engineering | Physical Sciences and Mathematics

\section{Publication Details}

Sun, W., Qian, C., Cui, X. Sherri., Wang, L., Wei, M., Casillas, G., Helmy, A. S. \& Ozin, G. A. (2016). Silicon monoxide-a convenient precursor for large scale synthesis of near infrared emitting monodisperse silicon nanocrystals. Nanoscale, 8 (6), 3678-3684.

\section{Authors}

Wei Sun, Chenxi Qian, Xiao Sherri Cui, Liwei Wang, Muan Wei, Gilberto Casillas, Amr S. Helmy, and Geoffrey A. Ozin 


\title{
Nanoscale
}

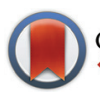

CrossMark $\leftarrow$ click for updates

Cite this: Nanoscale, 2016, 8, 3678

Received 22nd December 2015 Accepted 18th January 2016

DOI: $10.1039 / c 5 n r 09128 d$

www.rsc.org/nanoscale

\section{Silicon monoxide - a convenient precursor for large scale synthesis of near infrared emitting monodisperse silicon nanocrystals $\uparrow$}

\author{
Wei Sun, ${ }^{a}$ Chenxi Qian, ${ }^{a}$ Xiao Sherri Cui, ${ }^{b}$ Liwei Wang, ${ }^{a, c}$ Muan Wei, ${ }^{a, d}$ \\ Gilberto Casillas, ${ }^{e}$ Amr S. Helmy ${ }^{b}$ and Geoffrey A. Ozin*a
}

\begin{abstract}
While silicon nanocrystals ( $\mathrm{ncSi}$ ) embedded in silicon dioxide thin films have been intensively studied in physics, the potential of batch synthesis of silicon nanocrystals from the solid-state disproportionation of $\mathrm{SiO}$ powder has not drawn much attention in chemistry. Herein we describe some remarkable effects observed in the diffraction, microscopy and spectroscopy of SiO powder upon thermal processing in the temperature range $850-1100{ }^{\circ} \mathrm{C}$. Quantum confinement effects and structural changes of the material related to the size of the silicon nanocrystals nucleated and grown in this way were established by Photoluminescence (PL), Raman, FTIR and UV-Visible spectroscopy, PXRD and STEM, pinpointing that the most significant disproportionation transformations happened in the temperature range between 900 and $950{ }^{\circ} \mathrm{C}$. With this know-how a high yield synthesis was developed that produced polydispersions of decyl-capped, hexane-soluble silicon nanocrystals predominantly with near infrared (NIR) PL. Using sizeselective precipitation, these polydispersions were separated into monodisperse fractions, which allowed their PL absolute quantum yield (AQY) to be studied as a function of silicon nanocrystal size. This investigation yielded volcano-shaped plots for the AQY confirming the most efficient PL wavelength for ncSi to be located at around $820-830 \mathrm{~nm}$, which corresponded to a size of 3.5-4.0 nm. This work provides opportunities for applications of size-selected near infrared emitting silicon nanocrystals in biomedical imaging and photothermal therapy.
\end{abstract}

\section{Introduction}

Among the variety of semiconductor quantum dots targeted for applications in optoelectronics, ${ }^{1}$ biological imaging ${ }^{2}$ and chemical sensing, ${ }^{3}$ silicon nanocrystals (ncSi) are drawing increasing attention because of their earth-abundance, low cost, and purported lack of toxicity. ${ }^{4,5}$ Also improvements in lumines-

\footnotetext{
${ }^{a}$ Department of Chemistry, University of Toronto, 80 St. George Street, Toronto, Ontario M5S 3H6, Canada. E-mail: gozin@chem.utoronto.ca

${ }^{b}$ The Edward S. Rogers Sr. Department of Electrical and Computer Engineering, University of Toronto, 10 King's College Road, Toronto, Ontario M5S 3G4, Canada ${ }^{c}$ School of Marine Sciences, Guangxi University, Nanning, 530004, China ${ }^{d}$ Department of Materials Science and Engineering, University of Toronto, 184 College Street, Toronto, Ontario M5S 3E4, Canada

${ }^{e}$ Electron Microscopy Centre, University of Wollongong, New South Wales 2500, Australia

$\dagger$ Electronic supplementary information (ESI) available: Experimentals, Technicians' affiliations and instrumental descriptions for STEM imaging, XRD and PL comparison for different heating time at $900{ }^{\circ} \mathrm{C}$, a photo of the SiO powders, Raman spectra fitting method, STEM image for stacking fault. See DOI: 10.1039/ c5nr09128d
}

cent quantum yield of ncSi through surface-capping control, ${ }^{6-8}$ makes them interesting for quantum dot applications.

The synthetic strategies for making ncSi have been recently summarized by Mangolini. ${ }^{9}$ The groups of Ozin, ${ }^{8}$ Korgel $^{10}$ and Veinot (the pioneering group) ${ }^{11}$ have favoured batch syntheses that involve thermally treating hydridosilicate solids with formulae $\left(\mathrm{HSiO}_{1.5}\right)_{8}$ or $\left(\mathrm{HSiO}_{1.5}\right)_{n}$ in which silicon nanocrystals nucleate and grow within a silica matrix. Extraction with aqueous HF yields ncSi:H that can subsequently be surface functionalized by hydrosilylation with a terminal olefin to produce colloidally-stable, visibly-emitting ncSi:R. For many applications in biological imaging, near infrared (NIR) emission (from about $800 \mathrm{~nm}$ to $2500 \mathrm{~nm}$ ) is necessary to avoid overlap with biological background autofluorescence. ${ }^{12}$ Such ncSi were also demonstrated to exhibit a more effective photothermal effect than the visible-emitting analogues, which enhances the potential application of an effective photothermal therapy in conjunction with photoluminescence (PL) imaging. ${ }^{13,14}$ Unfortunately, production of near infrared emitting ncSi by the above methods usually requires very high temperatures above $1100{ }^{\circ} \mathrm{C}$. For example, Henderson et al. reported the heat treatment of $\left(\mathrm{HSiO}_{1.5}\right)_{n}$ sol-gel glass at 
$1200{ }^{\circ} \mathrm{C}$ for $1 \mathrm{~h}$ followed by annealing at $1100{ }^{\circ} \mathrm{C}$ for another $10 \mathrm{~h}$ resulted in ncSi with a PL peak maximum at $955 \mathrm{~nm}$. The maximum percentage mass yield of ncSi by this method was $10 \%$ after liberation from the silicon oxide matrix, ${ }^{15}$ which is considerable since the mass percent composition of $\mathrm{Si}$ in the precursor before heating is only slightly above $50 \%$, and there is additional loss of $\mathrm{SiH}_{4}$ co-generated during heating. Evidently, precursors with higher Si content may be advantageous for obtaining higher yields of ncSi. Indeed, silicon nanoclusters formed in silicon monoxide ( $\mathrm{SiO}$ ) films ${ }^{16-19}$ and other silicon sub-oxide $\left(\mathrm{SiO}_{x}, x<2\right)$ films,${ }^{20-23}$ usually prepared via thermal, plasma, and laser deposition, have been of interest in optical physics for applications as protective layers ${ }^{24,25}$ and in silicon based optoelectronics. ${ }^{26}$ Notably, SiO is also commercially available as powders in bulk quantities having a structure and properties that appears to be different from thin films. It has however received very little attention for the batch synthesis of freestanding ncSi. ${ }^{18}$ In this context, Liu et al. treated $\mathrm{SiO}$ powder at $1000{ }^{\circ} \mathrm{C}$ in $\mathrm{Ar}$ and obtained freestanding ncSi with visible PL. ${ }^{27}$ Dorofeev et al. expanded upon this work and reported a maximum PL QY of $12 \%$ for ncSi. ${ }^{28}$ Recently we successfully synthesized ncSi from $\mathrm{SiO}$ at a specific heating temperature of $900{ }^{\circ} \mathrm{C}$, the size distribution of which enabled a study on the size dependence of the absolute quantum yield (AQY) on passing from bulk to quantum confined silicon. ${ }^{29}$ However, much detailed information about the chemistry during such synthesis was left to be investigated.

Herein we describe an in-depth diffraction, microscopy and spectroscopy study that probes the effect of heat treatment of bulk quantities of $\mathrm{SiO}$ powder in the temperature range 850-1100 ${ }^{\circ} \mathrm{C}$. This insight enabled optimization of a high yield scalable synthesis for decyl-capped, hexane-soluble silicon nanocrystal $\left(\mathrm{ncSi}_{\mathrm{S}} \mathrm{C}_{10}\right)$ polydispersions that predominantly display NIR PL. Size-selective precipitation of these polydisperse $\mathrm{ncSi} \mathrm{C}_{10}$ samples yielded monodisperse fractions, the study of which provided a unique insight into the optimum PL efficiency versus emission wavelength, as well as guidance on the tuning of size distributions through the choice of the synthetic conditions to target a specific range of PL wavelengths.

\section{Results and discussion}

\subsection{Dependence of ncSi formation on thermal treatment temperature}

The commercial SiO powder precursor used by $\mathrm{Liu}^{27}$ and Dorofeev $^{28}$ were claimed to be amorphous, ${ }^{30}$ however, their powder X-ray diffraction (PXRD) results clearly show a crystalline silicon phase prior to any thermal treatment or at very low temperatures $\left(200{ }^{\circ} \mathrm{C}\right)$. It is conceivable in this earlier work that the size and yield of the resultant ncSi after thermal annealing would sensitively depend on the presence of the initial ncSi, which could act as nucleation sites as well as possibly influence the thermal disproportionation. In contrast, the SiO powder we used in this study were amorphous from the beginning, where only two broad humps centred at $\sim 23$ and $\sim 51$ degrees could be seen in the PXRD pattern of the commercial SiO precursor. ${ }^{29}$ This ensures that the production of ncSi mainly originates from the thermally induced disproportionation reaction shown in stoichiometric form below:

$$
2 \mathrm{SiO} \rightarrow \mathrm{Si}+\mathrm{SiO}_{2}
$$

Before heating, the SiO might comprise a matrix of small clusters of $\mathrm{Si}$ and $\mathrm{SiO}_{2}{ }^{31}$ with insufficient crystalline order or size to be detected by PXRD. When thermally processed at $875{ }^{\circ} \mathrm{C}$ in an atmosphere of $5 \% \mathrm{H}_{2}$ in $\mathrm{Ar}$ (the optimal protective gas that can also enhance crystal quality ${ }^{32,33}$ ) and kept at this temperature for $1 \mathrm{~h}$, only one new broad diffraction peak at $\sim 28$ degrees emerged, corresponding to the Si (111) diffraction, indicating the genesis of embryonic ncSi forming inside the matrix. Above $900{ }^{\circ} \mathrm{C}$ the (111), (220) and (311) diffraction peaks grow larger and sharper, which continues as the temperature was elevated, and are sensitive to even a small change at this threshold temperature. As shown in Fig. 1, a $20{ }^{\circ} \mathrm{C}$ increase of processing temperature even with a shorter processing time led to an observable increase of the (111) peak relative to the amorphous hump adjacent to it. The detailed growth of ncSi was quantified by full profile fitting the (111) peaks to obtain the temperature dependence of the unit cell size of the ncSi and by applying the Scherrer equation to the peak broadening to obtain an estimate of the ncSi size. ${ }^{29}$ While there could be other sources of peak broadening for example, associated with dislocations, stacking faults and twinning, ${ }^{34}$ there is no doubt higher temperatures favour the formation of larger ncSi with increasing unit cell dimensions that converge towards the bulk Si value of $5.4307 \AA$.

During the thermal treatment, the broad PXRD peak around 51 degrees gradually diminished and is most likely associated with amorphous $\mathrm{Si}$ clusters or a $\mathrm{SiO}_{x}$ interface between domains of ncSi and $\mathrm{SiO}_{2} \cdot{ }^{18}$ Note that with increasing reaction time further coarsening ${ }^{35}$ or "pseudo-Ostwald ripening”"23 of ncSi is not rare. We observe that longer heating times at the same temperature result in larger size ncSi, revealed by sharper peaks in PXRD and a red-shifted peak in PL spectra (see $\mathrm{ESI} \dagger$ ).

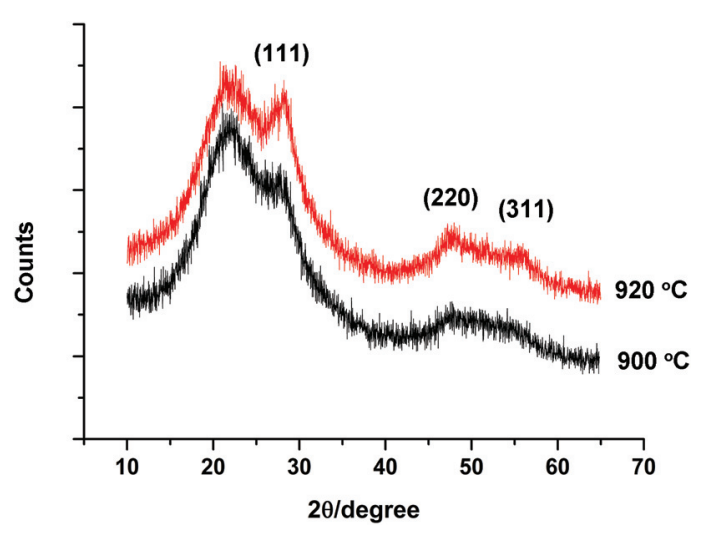

Fig. 1 Representative Powder X-ray diffraction patterns of SiO powder processed at $900^{\circ} \mathrm{C}$ and $920^{\circ} \mathrm{C}$. 
As the broad diffraction peak at $\sim 21$ degrees seemed slightly shifted to lower angles as the heating temperature was elevated, ${ }^{29}$ approaching the position for amorphous $\mathrm{SiO}_{2}$, the redistribution of the structure towards ncSi in $\mathrm{SiO}_{2}$ matrix is conceivable. So we investigated the characteristic peak assigned to $\mathrm{Si}-\mathrm{O}-\mathrm{Si}$ in the IR spectra which reflects the bond angle information.

As can be seen in Fig. 2 as the temperature increases, the $\mathrm{Si}-\mathrm{O}-\mathrm{Si}$ stretching mode appeared sharper and the peak centre shifted to higher wave numbers, from $1028 \mathrm{~cm}^{-1}$ for the unheated sample to $1098 \mathrm{~cm}^{-1}$ for a sample thermally processed at $1100{ }^{\circ} \mathrm{C}$. The position of the peak has been correlated with the angle $2 \theta$ between the two $\mathrm{Si}$ atoms separated by a bridging $\mathrm{O}$ atom in Fitch's work: ${ }^{36}$

$$
\nu=\nu_{0} \sin \theta
$$

where $\nu_{0}$ was $1116.5 \mathrm{~cm}^{-1}$ when $\theta$ was $75^{\circ}$ for a $\mathrm{SiO}_{2}$ grown at $1150{ }^{\circ} \mathrm{C}$ in this work. The blue shifting and sharpening of the $\mathrm{Si}-\mathrm{O}-\mathrm{Si}$ stretching frequency observed during the disproportionation $\mathrm{SiO} \rightarrow \mathrm{Si}+\mathrm{SiO}_{2}$ reaction indicates the formation of a more well-defined $\mathrm{SiO}_{2}$ phase ${ }^{20,37}$ from a poorly ordered SiO phase with a range of $\mathrm{Si}-\mathrm{O}-\mathrm{Si}$ bond angles. ${ }^{38}$ With the change of the structure, we also observed an accompanying colour change of the matrix from reddish-brown to dark brown (see photo in ESI $\dagger$ ), which is manifest as changes in the reflectance spectra especially at longer wavelengths that begins above $850^{\circ} \mathrm{C}$, and plateaus above $950^{\circ} \mathrm{C}$, as shown in Fig. 3 .

Another informative technique for probing the formation of ncSi during the thermal induced disproportionation of $\mathrm{SiO}$ is Raman spectroscopy. ${ }^{39}$ All the thermally treated SiO powder samples have multiple broad peaks, shown in Fig. 4. The detailed assignment ${ }^{33,40}$ of Raman peaks is shown in Fig. 5a: the longitudinal acoustic (LA) mode centered at $\sim 300 \mathrm{~cm}^{-1}$, the longitudinal optical (LO) mode at $\sim 425 \mathrm{~cm}^{-1}$, and the strong transverse optical (TO a-Si) mode at $\sim 475 \mathrm{~cm}^{-1}$ are all from the amorphous $\mathrm{Si}$ contribution, while a single asymmetric transverse optical (c-TO) mode, which is related to the ncSi, is slightly downshifted from the crystalline Si wafer mode at $521 \mathrm{~cm}^{-1}$, to around $516-517 \mathrm{~cm}^{-1}$, indicating the effect of

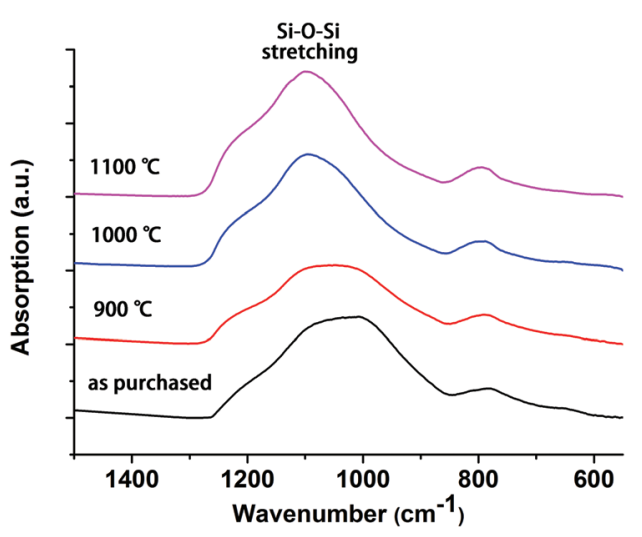

Fig. 2 ATR-FTIR spectra of SiO thermally processed at different temperatures.

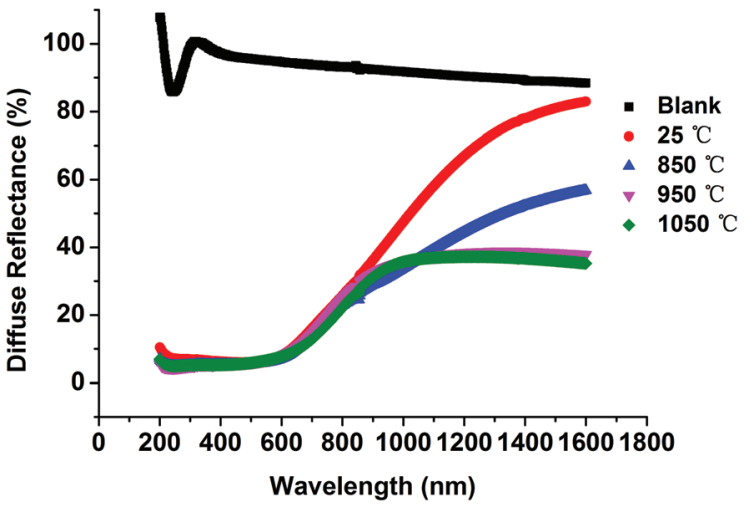

Fig. 3 Diffuse reflectance spectra of $\mathrm{SiO}$ thermally processed at different temperatures.

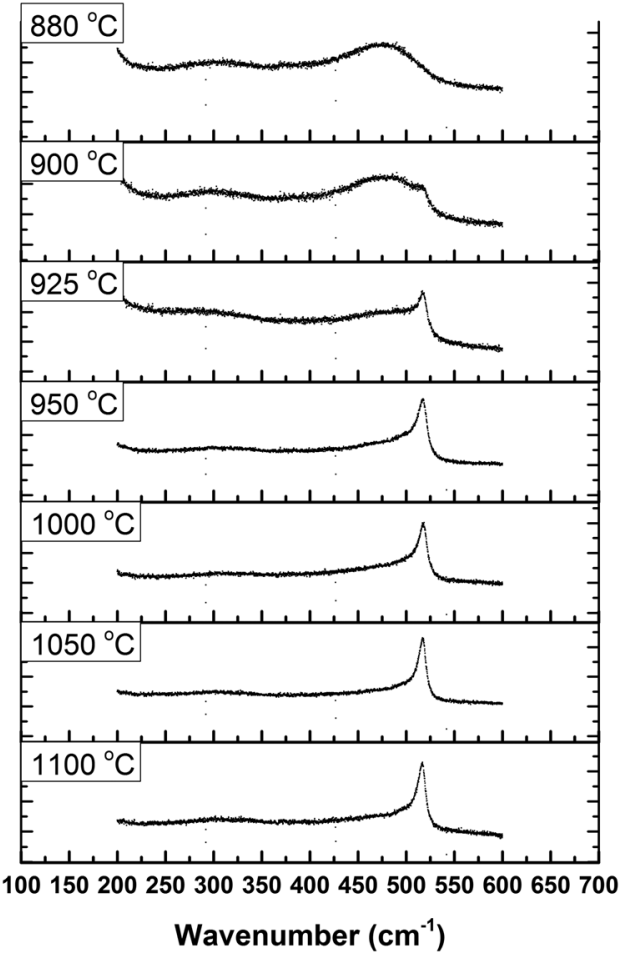

Fig. 4 Raman spectra of SiO powder thermally processed at different temperatures.

phonon confinement. ${ }^{41,42}$ Multiple peak fitting was performed for each Raman spectrum except for that of the sample thermally processed at $850{ }^{\circ} \mathrm{C}$, as shown in Fig. 5a, following a reported Fano model. ${ }^{43}$ (see detailed fitting method in ESI $\dagger$ ).

We found that the SiO powder precursor contains no detectable crystallized Si initially but rather only amorphous $\mathrm{Si}$, even if thermally processed at $880^{\circ} \mathrm{C}$. When the powder was thermally processed above $900{ }^{\circ} \mathrm{C}$, the Raman peak for crystalline Si became observable and could be well-fitted, indicating formation of significant amounts of ncSi, consistent with our PXRD result. As expected, higher temperature led to $\mathrm{Si}(0)$ within the oxide matrix with a concomitantly higher crystal 
a

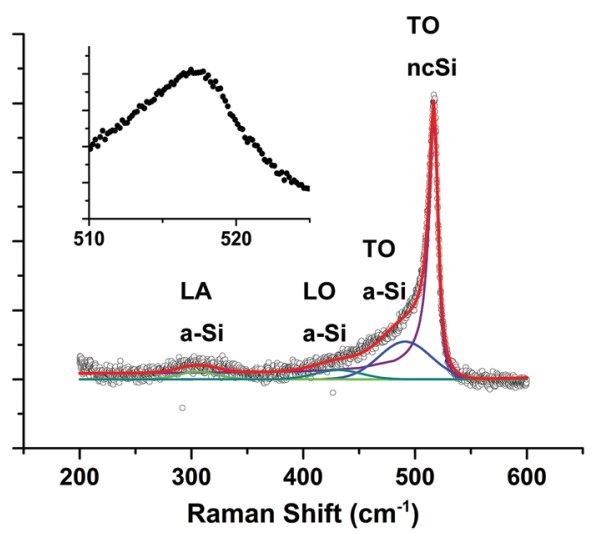

b

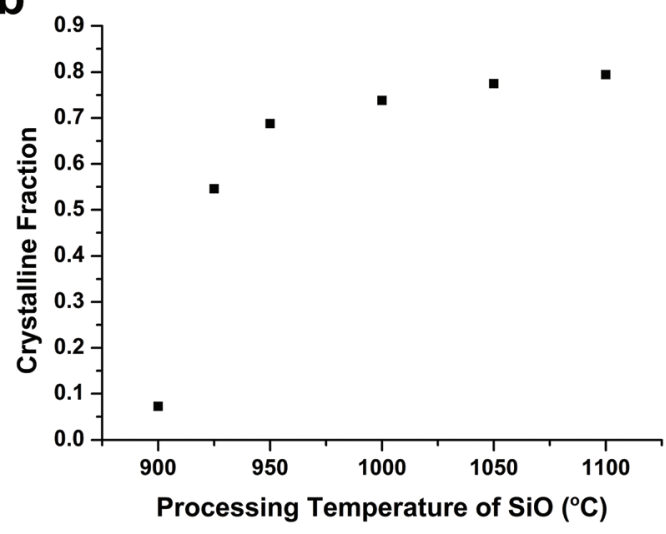

Fig. 5 (a) A representative fitting of the Raman spectrum obtained from $\mathrm{SiO}$ powder thermally processed at $1050{ }^{\circ} \mathrm{C}$, where a-Si represents amorphous $\mathrm{Si}$, dots are obtained data points, and the curve overlapping with the dots is the cumulative fitting curve. The inset shows the ncSi TO mode position. (b) Calculated crystalline fraction versus processing temperature during the synthesis.

fraction calculated using the equation:

$$
F_{\mathrm{c}}=I_{\mathrm{c}} /\left(I_{\mathrm{c}}+\alpha I_{\mathrm{a}}\right)
$$

where $\alpha=0.8$ is the Raman cross section ratio for phonon excitation of crystalline $\mathrm{Si}\left(I_{\mathrm{c}}\right)$ to the amorphous $\left(I_{\mathrm{a}}\right)$ components. ${ }^{44}$ Again we consistently found that drastic change occurred between 900 and $950{ }^{\circ} \mathrm{C}$, and plateaued above $950{ }^{\circ} \mathrm{C}$. Though $1 \mathrm{~h}$ of heating did not lead to $100 \%$ yield of the crystalline ncSi phase, it nevertheless did produce significant amounts of ncSi as a precursor for the subsequent production of size-separated, colloidally-stable, organic-capped and brightly-luminescent ncSi:R with the NIR PL range of interest in this investigation as discussed below.

\subsection{Size-separated colloidally stable ncSi with NIR PL}

With the information derived from the various characterization techniques discussed above, it is clear that the size and yield of ncSi are sensitive to the heating temperature and time: $1 \mathrm{~h}$ at $\sim 900{ }^{\circ} \mathrm{C}$ is a threshold temperature for significant crystallization whereas for the same time below $\sim 850^{\circ} \mathrm{C}$, crystallization barely occurred, and we observed no PL from the ncSi produced from SiO thermally processed at $950{ }^{\circ} \mathrm{C}$ within our detector's working wavelength range. Therefore the processing temperatures of 900,920 , and $925^{\circ} \mathrm{C}$ were chosen as the standard protocols for producing ncSi. After the liberation of ncSi from the $\mathrm{SiO}_{2}$ matrix by aqueous $\mathrm{HF}$ etching, ${ }^{8}$ turbid dispersions of ncSi:H could be obtained in common organic solvents such as toluene and aliphatic hydrocarbons. Note that this synthesis approach has several advantages over the $\left(\mathrm{HSiO}_{1.5}\right)_{n}$ precursor, which was synthesized from $\mathrm{HSiCl}_{3}$ and processed with several steps before HF etching. ${ }^{45-47}$ Table 1 lists several comparisons between the two methods. The origin of the relatively low yield of ncSi:H product for both methods we believe is during the aqueous HF extraction and transfer of the dispersion to the organic solvent, however the yield of ncSi:H from the $\mathrm{SiO}$ precursor is consistently higher than $\left(\mathrm{HSiO}_{1.5}\right)_{n}$ due to the higher atom ratio of $\mathrm{Si}$, and the experimental procedure is much easier to manage.

The ncSi:H devoid of organic ligands is not colloidally stable whereas ncSi:R with organic capping groups becomes colloidally stable. This was achieved by hydrosilylation using 1-decene as the non-polar solvent for both the extraction and as the reactant at $170{ }^{\circ} \mathrm{C} .{ }^{48}$ Following this procedure the dispersion became clear.

$\mathrm{NcSi}: \mathrm{C}_{10}$ remained colloidally stable after re-dispersion in hexane. The size of a statistically meaningful population of the crystalline ncSi: $\mathrm{C}_{10}$ was measured by bright-field (BF) scanning transmission electron microscopy (STEM). The mean size of ncSi: $\mathrm{C}_{10}$ obtained from $\mathrm{SiO}$ thermally processed at $900{ }^{\circ} \mathrm{C}$ determined in this way is $3.5 \mathrm{~nm}$ as we reported elsewhere, ${ }^{29}$ which is larger than the value calculated by Scherrer analysis of PXRD line widths ( $\sim \mathrm{nm})$. This discrepancy might arise from the occurrence of stacking faults and twinning observed in the larger ncSi which can contribute additional line broadening in PXRD $^{34}$ (see ESI† for STEM image of large ncSi). The PL wavelength and the AQY of the ensemble was determined to be $834 \mathrm{~nm}$ and $12-14 \%$ respectively, which is consistent with a ncSi: $\mathrm{C}_{10}$ size of $3.5-4 \mathrm{~nm} .{ }^{49}$ It is interesting that in the ensemble prepared from $\mathrm{SiO}$ some very small ncSi: $\mathrm{C}_{10}$ still displayed crystalline order. In our previous report, using the $\mathrm{HSiO}_{1.5}$ precursor, we were hardly able to identify crystalline

Table 1 ncSi from $\left(\mathrm{HSiO}_{1.5}\right)_{n}$ versus $\mathrm{SiO}$ precursors

\begin{tabular}{|c|c|c|c|c|c|c|}
\hline & $T\left({ }^{\circ} \mathrm{C}\right)$ & Precursor mass (g) & ncSi yield (g) & \% Mass yield & $\mathrm{PL}(\mathrm{nm})^{a}$ & Pre-processing \\
\hline$\left(\mathrm{HSiO}_{1.5}\right)_{n}$ & 1050 & 0.60 & 0.015 & 2.5 & 733 & Yes \\
\hline $\mathrm{SiO}$ & 900 & 0.30 & 0.020 & 6.7 & 869 & No \\
\hline
\end{tabular}

${ }^{a}$ After etching in HF solution for $1 \mathrm{~h} 30 \mathrm{~min}$. 


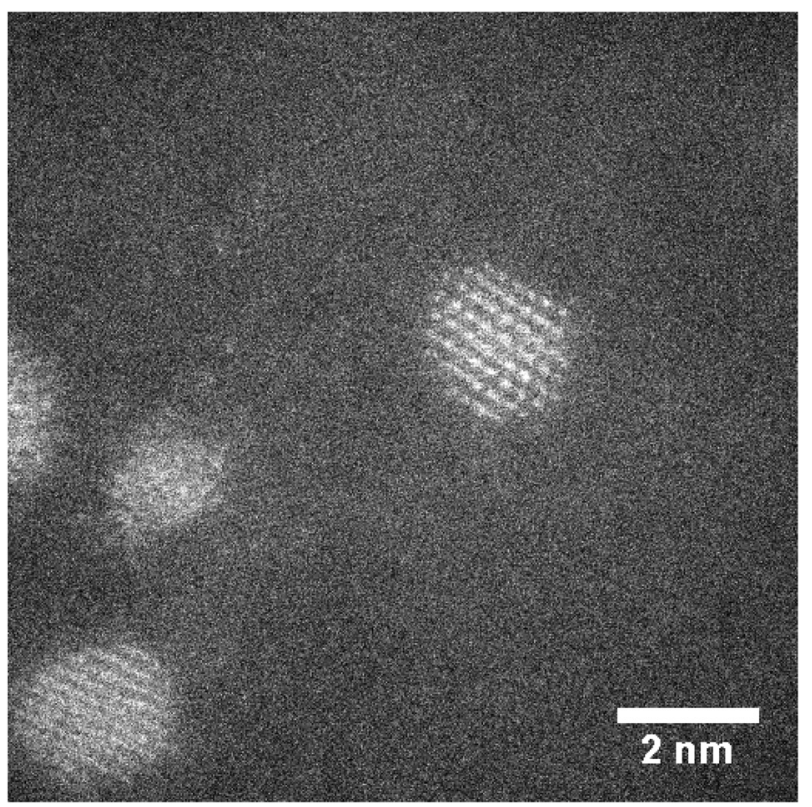

Fig. 6 HAADF-STEM image showing $\mathrm{ncSi}: \mathrm{C}_{10}$ smaller than $2.5 \mathrm{~nm}$ displaying clear lattice fringes.

order for ncSi: $\mathrm{C}_{10}$ smaller than $\sim 2.5 \mathrm{~nm},{ }^{50}$ however in this work the use of a probe-corrected microscope allowed us to confirm that these small particles on a graphene TEM grid ${ }^{51}$ are also crystalline, as shown in the HAADF-STEM image in Fig. 6.

We performed size separation to several ensemble dispersions obtained from $\mathrm{SiO}$ processed at different temperatures using the size selective precipitation method. ${ }^{45}$ In the top plot of Fig. 7 it can be seen from the right to the left that the PL wavelength maximum of ncSi: $\mathrm{C}_{10}$ blue shifted monotonically from $\sim 900 \mathrm{~nm}$ to $\sim 740 \mathrm{~nm}$, consistent with the quantum size effect (QSE) expected on decreasing the size of $\mathrm{ncSi}_{\mathrm{i}} \mathrm{C}_{10}$ from the largest to the smallest. Since the measurements were conducted at room temperature and the ncSi are freestanding, temperature and interface effects are excluded. Of special interest is the amonotonic trend observed for the $\mathrm{AQY}$, which switches on from essentially zero for $\mathrm{ncSi}^{-\mathrm{C}_{10}}$ at the wavelength of $\sim 900 \mathrm{~nm}$, corresponding to the size around $5 \mathrm{~nm},{ }^{29}$ increases monotonically to reach a maximum around $820 \mathrm{~nm}$ and then decreases monotonically to the smallest studied approaching $725 \mathrm{~nm}$, with a value again close to zero.

We previously attribute this volcano like behaviour of the size dependent PL AQY of ncSi: $\mathrm{C}_{10}$ to how the counterbalancing radiative and non-radiative contributions to photo-excited electron-hole recombination emission was affected by the size of the ncSi: $\mathrm{C}_{10}$. These three regions of the volcano-shaped plot are believed to respectively define the (i) transition from bulk non-emissive silicon to quantum confined emissive silicon, (ii) increasing spatial confinement of electron-hole pairs enhancing radiative recombination, and (iii) increasing contributions

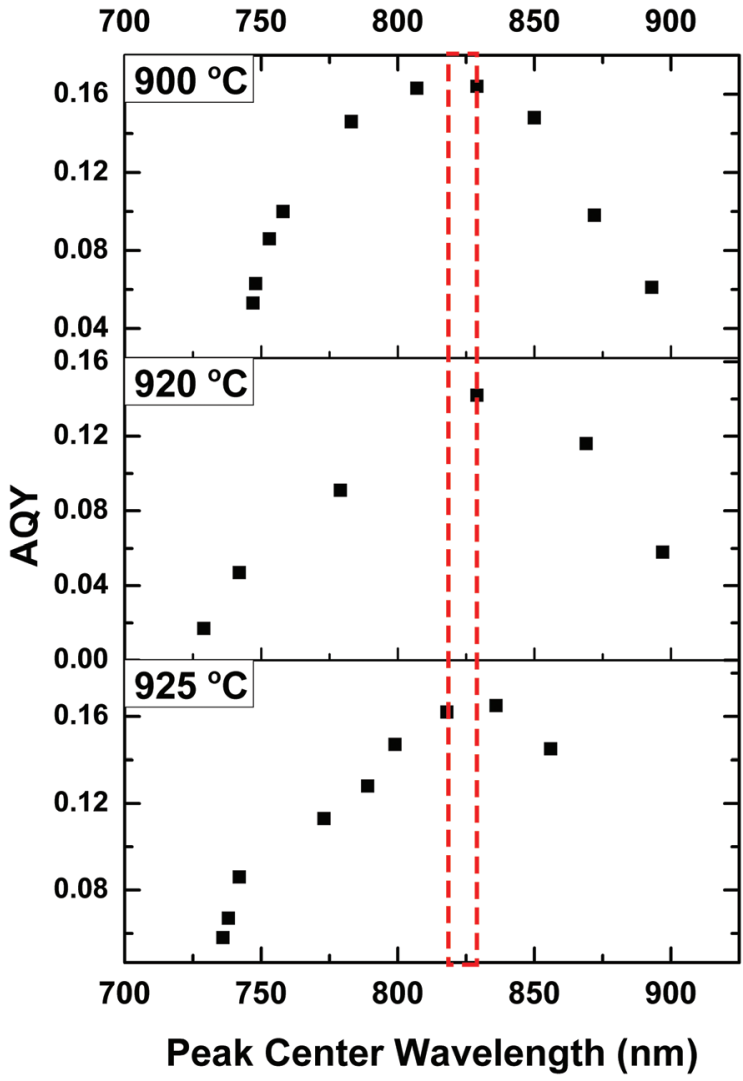

Fig. 7 Absolute quantum yield of photoluminescence as a function of peak centre wavelength. The $\mathrm{SiO}$ powder was processed at 900, 920, $925^{\circ} \mathrm{C}$ for $1 \mathrm{~h}, 35 \mathrm{~min}$, and $30 \mathrm{~min}$, and etched for $2 \mathrm{~h} 50 \mathrm{~min}, 2 \mathrm{~h}$ $50 \mathrm{~min}$, and $2 \mathrm{~h} 30 \mathrm{~min}$, respectively. The dashed column indicates the samples where the absolute quantum yield was maximum.

of organic-capping group vibrations and surface defects favouring non-radiative recombination. ${ }^{29,45}$

The volcano tops at $820-830 \mathrm{~nm}$ in Fig. 7 effectively pinpoints where the opposing factors of radiative recombination and non-radiative recombination balance each other. Although the ncSi were produced under different conditions, the position of the maximum in the volcano-shaped plots are very close, thus confirming the credibility of such behaviour, excluding the possibility of artefacts originated from a specific synthetic condition. Therefore, at this wavelength, the PL of ncSi is most efficient. However, the most complete profile of the volcano-shaped plot was only observed for the ncSi from the $\mathrm{SiO}$ processed at $900{ }^{\circ} \mathrm{C}$. The temperature of $920{ }^{\circ} \mathrm{C}$ and $925{ }^{\circ} \mathrm{C}$ only yielded part of the volcano-shape, without showing the point where the AQY switched on. Therefore, the optimum processing temperature to produce colloidally-stable ncSi with PL spanning the whole efficient luminescence wavelength range should be exactly $900{ }^{\circ} \mathrm{C}$. Nevertheless, if one aims at obtaining PL within the NIR range, $920{ }^{\circ} \mathrm{C}$ could be optimum, as shown in Fig. 8, in which the most concentrated fractions exhibit longer PL emission wavelength over $800 \mathrm{~nm}$, corresponding with the results in Fig. 7. 


\section{Concentrated}

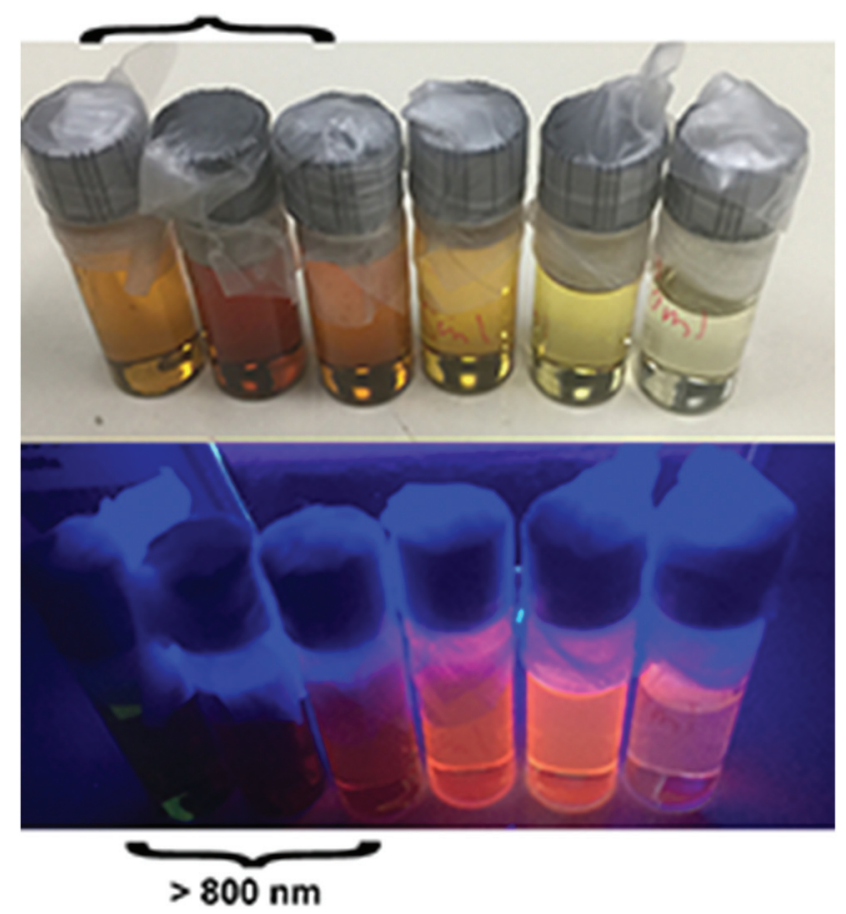

Fig. 8 Photos of size separated ncSi: $\mathrm{C}_{10}$ fractions under room light (upper) and under UV light (lower).

\section{Conclusions}

The thermally-induced solid-state disproportionation of commercially available SiO, according to the simplified reaction scheme $2 \mathrm{SiO} \rightarrow \mathrm{Si}+\mathrm{SiO}_{2}$ provides a convenient gram scale batch synthesis of ncSi encapsulated by a $\mathrm{SiO}_{2}$ matrix. The $900{ }^{\circ} \mathrm{C}$ processing temperature serves as the threshold temperature for ncSi nucleation and growth, with the most drastic changes of structure occurring between $900{ }^{\circ} \mathrm{C}$ and $950{ }^{\circ} \mathrm{C}$. Above $950^{\circ} \mathrm{C}$, large ncSi with no detectable PL dominate, with properties resembling those of bulk Si. Subsequent aqueous $\mathrm{HF}$ etching of the $\mathrm{SiO}_{2}$ matrix liberates ncSi:H, which can be hydrosilated with a terminal olefin such as 1-decene to form polydispersions of colloidally-stable, organic-capped brightlyphotoluminescent $\mathrm{ncSi}: \mathrm{C}_{10}$. These polydispersions can be sorted by size selective precipitation methods using a solvent anti-solvent strategy into monodispersions of $\mathrm{ncSi}^{\mathrm{C}} \mathrm{C}_{10}$ that display characteristic QSE in their PL spectra. By controlling the temperature and time of the thermal treatment of SiO as well as the aqueous HF etching time it has proven possible to obtain monodispersions of $\mathrm{ncSi}^{\mathrm{C}} \mathrm{C}_{10}$ that display PL predominantly throughout the NIR wavelength range. Here it has been discovered that the size-dependence of the PL AQY displays a volcano-shape, which maximises at a wavelength of 820-830 $\mathrm{nm}$. This all bodes well for the development of a scalable synthesis of size-selected near infrared emitting silicon nanocrystals with potential applications in biomedical imaging and photothermal therapy.

\section{Acknowledgements}

GAO is Government of Canada Research Chair in Materials Chemistry and Nanochemistry. The strong and sustained support of the Natural Sciences and Engineering Research Council of Canada is deeply appreciated. Chenxi Qian and Wei Sun are grateful to the Connaught Foundation for graduate fellowships. This research used equipment funded by the Australian Research Council (ARC) - Linkage, Infrastructure, Equipment and Facilities (LIEF) grant LE120100104 located at the UOW Electron Microscopy Centre. STEM imaging conducted by Dr Larios-Rodriguez, E is appreciated.

\section{References}

1 D. V. Talapin, J.-S. Lee, M. V. Kovalenko and E. V. Shevchenko, Chem. Rev., 2010, 110, 389-458.

2 X. Michalet, F. F. Pinaud, L. A. Bentolila, J. M. Tsay, S. Doose, J. J. Li, G. Sundaresan, A. M. Wu, S. S. Gambhir and S. Weiss, Science, 2005, 307, 538-544.

3 W. C. W. Chan and S. Nie, Science, 1998, 281, 2016-2018.

4 A. N. Shubenkov, S. B. Korovin, E. R. Andreeva, L. B. Buravkova and V. I. Pustovoy, Biophysics, 2014, 59, 105-109.

5 A. M. Derfus, W. C. W. Chan and S. N. Bhatia, Nano Lett., 2003, 4, 11-18.

6 R. J. Anthony, D. J. Rowe, M. Stein, J. Yang and U. Kortshagen, Adv. Funct. Mater., 2011, 21, 4042-4046.

7 M. L. Mastronardi, E. J. Henderson, D. P. Puzzo, Y. Chang, Z. B. Wang, M. G. Helander, J. Jeong, N. P. Kherani, Z. Lu and G. A. Ozin, Small, 2012, 8, 3647-3654.

8 M. L. Mastronardi, F. Maier-Flaig, D. Faulkner, E. J. Henderson, C. Kübel, U. Lemmer and G. A. Ozin, Nano Lett., 2011, 12, 337-342.

9 L. Mangolini, J. Vac. Sci. Technol., B, 2013, 31, 020801.

10 C. M. Hessel, D. Reid, M. G. Panthani, M. R. Rasch, B. W. Goodfellow, J. Wei, H. Fujii, V. Akhavan and B. A. Korgel, Chem. Mater., 2011, 24, 393-401.

11 E. J. Henderson, J. A. Kelly and J. G. C. Veinot, Chem. Mater., 2009, 21, 5426-5434.

12 A. M. Smith, M. C. Mancini and S. Nie, Nat. Nano, 2009, 4, 710-711.

13 S. Regli, J. A. Kelly, A. M. Shukaliak and J. G. C. Veinot, J. Phys. Chem. Lett., 2012, 3, 1793-1797.

14 L. Han, M. Zeman and A. H. M. Smets, Nanoscale, 2015, 7, 8389-8397.

15 C. M. Hessel, E. J. Henderson and J. G. C. Veinot, Chem. Mater., 2006, 18, 6139-6146.

16 E. A. Mikhantiev, S. V. Usenkov and N. L. Shwartz, 2012.

17 K. Schulmeister and W. Mader, J. Non-Cryst. Solids, 2003, 320, 143-150.

18 A. Hohl, T. Wieder, P. A. van Aken, T. E. Weirich, G. Denninger, M. Vidal, S. Oswald, C. Deneke, J. Mayer and H. Fuess, J. Non-Cryst. Solids, 2003, 320, 255-280. 
19 J. Wang, X. F. Wang, Q. Li, A. Hryciw and A. Meldrum, Philos. Mag., 2007, 87, 11-27.

20 T. R. Roschuk, J. Wojcik, E. A. Irving, M. Flynn and P. Mascher, 2004.

21 N. Saxena, A. Agarwal and D. Kanjilal, Phys. B, 2011, 406, 2148-2151.

22 N. Daldosso, G. Das, S. Larcheri, G. Mariotto, G. Dalba, L. Pavesi, A. Irrera, F. Priolo, F. Iacona and F. Rocca, J. Appl. Phys., 2007, 101, 113510.

23 D. Yu, S. Lee and G. S. Hwang, J. Appl. Phys., 2007, 102, 084309.

24 C. A. Wang, R. K. Huang, D. A. Shiau, M. K. Connors, P. G. Murphy, P. W. O’Brien, A. C. Anderson, D. M. DePoy, G. Nichols and M. N. Palmisiano, Appl. Phys. Lett., 2003, 83, 1286-1288.

25 H. Shibayama, S. Hasuo and T. Yamaoka, Appl. Phys. Lett., 1985, 47, 429-430.

26 L. Pavesi, L. Dal Negro, C. Mazzoleni, G. Franzo and F. Priolo, Nature, 2000, 408, 440-444.

27 S.-M. Liu, Y. Yang, S. Sato and K. Kimura, Chem. Mater., 2006, 18, 637-642.

28 S. G. Dorofeev, A. A. Ischenko, N. N. Kononov and G. V. Fetisov, Curr. Appl. Phys., 2012, 12, 718-725.

29 W. Sun, C. Qian, L. Wang, M. Wei, M. L. Mastronardi, G. Casillas, J. Breu and G. A. Ozin, Adv. Mater., 2015, 27, 746-749.

30 M. Nagamori, J. A. Boivin and A. Claveau, J. Non-Cryst. Solids, 1995, 189, 270-276.

31 A. Hohl, T. Wieder, P. A. van Aken, T. E. Weirich, G. Denninger, M. Vidal, S. Oswald, C. Deneke, J. Mayer and H. Fuess, J. Non-Cryst. Solids, 2003, 320, 255-280.

32 Y. Li, P. Liang, Z. Hu, S. Guo, Q. You, J. Sun, N. Xu and J. Wu, Appl. Surf. Sci., 2014, 300, 178-183.

33 L. J. Borrero-González, L. A. O. Nunes, M. R. B. Andreeta, J. Wojcik, P. Mascher, Y. A. Pusep, D. Comedi and F. E. G. Guimarães, J. Appl. Phys., 2010, 108, 013105.

34 A. K. Singh and D. M. R. Laboratory, Advanced X-ray Techniques in Research and Industry, Capital Publishing Company, 2006.

35 S. Mukherjee and B. R. Cooper, Mater. Sci. Eng., A, 1998, 248, 101-114.
36 J. T. Fitch, G. Lucovsky, E. Kobeda and E. A. Irene, J. Vac. Sci. Technol., B, 1989, 7, 153-162.

37 A. Sassella, A. Borghesi, F. Corni, A. Monelli, G. Ottaviani, R. Tonini, B. Pivac, M. Bacchetta and L. Zanotti, J. Vac. Sci. Technol., A, 1997, 15, 377-389.

38 K. AlKaabi, D. L. V. K. Prasad, P. Kroll, N. W. Ashcroft and R. Hoffmann, J. Am. Chem. Soc., 2014, 136, 3410-3423.

39 R. Anthony and U. Kortshagen, Phys. Rev. B: Condens. Matter, 2009, 80, 115407.

40 Y. Duan, J. F. Kong and W. Z. Shen, J. Raman Spectrosc., 2012, 43, 756-760.

41 K. W. Adu, H. R. Gutiérrez, U. J. Kim, G. U. Sumanasekera and P. C. Eklund, Nano Lett., 2005, 5, 409-414.

42 L. Han, M. Zeman and A. H. M. Smets, Appl. Phys. Lett., 2015, 106, 213106.

43 D. M. Sagar, J. M. Atkin, P. K. B. Palomaki, N. R. Neale, J. L. Blackburn, J. C. Johnson, A. J. Nozik, M. B. Raschke and M. C. Beard, Nano Lett., 2015, 15, 1511-1516.

44 L. J. Borrero-González, L. A. O. Nunes, M. R. B. Andreeta, J. Wojcik, P. Mascher, Y. A. Pusep, D. Comedi and F. E. G. Guimarães, J. Appl. Phys., 2010, 108, 013105.

45 M. L. Mastronardi, F. Maier-Flaig, D. Faulkner, E. J. Henderson, C. Kubel, U. Lemmer and G. A. Ozin, Nano Lett., 2012, 12, 337-342.

46 W. Sun, C. X. Qian, M. L. Mastronardi, M. Wei and G. A. Ozin, Chem. Commun., 2013, 49, 11361-11363.

47 C. Qian, W. Sun, L. Wang, C. Chen, K. Liao, W. Wang, J. Jia, B. D. Hatton, G. Casillas, M. Kurylowicz, C. M. Yip, M. L. Mastronardi and G. A. Ozin, J. Am. Chem. Soc., 2014, 136, 15849-15852.

48 W. Sun, C. Qian, M. L. Mastronardi, M. Wei and G. A. Ozin, Chem. Commun., 2013, 49, 11361-11363.

49 W. D. A. M. de Boer, D. Timmerman, K. Dohnalova, I. N. Yassievich, H. Zhang, W. J. Buma and T. Gregorkiewicz, Nat. Nanotechnol., 2010, 5, 878-884.

50 M. L. Mastronardi, F. Hennrich, E. J. Henderson, F. MaierFlaig, C. Blum, J. Reichenbach, U. Lemmer, C. Kübel, D. Wang, M. M. Kappes and G. A. Ozin, J. Am. Chem. Soc., 2011, 133, 11928-11931.

51 M. G. Panthani, C. M. Hessel, D. Reid, G. Casillas, M. JoséYacamán and B. A. Korgel, J. Phys. Chem. C, 2012, 116, 22463-22468. 